\title{
Elevated Lipoprotein (a) in Cardiac Outcomes: A Review
}

Sahoo Alor ${ }^{1}$, Strong Laura ${ }^{1}$, Jensen Alexander ${ }^{2}$, Flaherty Daniel², Anand Mukul ${ }^{1}$, Alromheen Hassan ${ }^{1}$, Singh, Sarabjeet $^{3 *}$

${ }^{1}$ Central Cardiology Medical Center, Bakersfield, CA.

${ }^{2}$ Touro University California, Vallejo, CA.

${ }^{3}$ Central Cardiology Medical Center, Cedars-Sinai, College of Osteopathic Medicine, Touro University California, Vallejo, CA.

*Corresponding author: Singh Sarabjeet, Central Cardiology Medical Center, 2901 Sillect Avenue Suite 100, Bakersfield, CA 93308, USA Received date: September 21, 2020; Accepted date: September 25, 2020; Published date: October 01, 2020

Citation: Sahoo Alor, Strong Laura, Jensen Alexander, Flaherty Daniel, Anand Mukul, Alromheen Hassan, Singh, Sarabjeet (2020) Elevated Lipoprotein (a) in Cardiac Outcomes: A Review. J, Clinical Cardiology and Cardiovascular Interventions, 3(8); Doi:10.31579/2641-0419/083

Copyright: (C) 2020 Singh Sarabjeet, This is an open access article distributed under the Creative Commons Attribution License, which permits unrestricted use, distribution, and reproduction in any medium, provided the original work is properly cited.

\section{Abstract}

Context: Elevated lipoprotein (a) [Lp(a)] levels is an often-ignored risk factor for major adverse cardiac events (MACEs) in humans. Even after accounting for established risk factors (discussed in the text), some residual risk can still be independently attributed to elevated $\mathrm{Lp}(\mathrm{a})$ levels.

Current guidelines dictating normal and elevated $\mathrm{Lp}$ (a) levels and subsequent treatment have proven haphazard due to unstandardized studies. Many studies offer cutoff values in units $\mathrm{mg} / \mathrm{dL}$, which do not account for the heterogeneity of $\mathrm{Lp}(\mathrm{a})$. Interpretation of elevated $\mathrm{Lp}(\mathrm{a})$ necessitates consideration of ethnicity necessary for proper predictions. Numerous studies detail the effects of elevated $\mathrm{Lp}(\mathrm{a})$ in relation to myocardial infarction, aortic valve stenosis, and atherosclerosis, among other conditions. This article aims to clarify the numerous cutoffs and guidelines presented.

Methods: Searches were primarily conducted through Google, PubMed.gov, and cochrane.org.

Results: Elevated Lp(a) seems to correlate with the incidence of MACEs and should be considered when assessing risk. Specific cutoff values remain quite unclear.

Conclusions: We urge for further detailed investigation on the effects of elevated Lp(a) on cardiac outcomes with the use of isoform independent assays. Particular attention should be given to ethnicity when assigning risk cutoffs for cardiac conditions. Proprotein convertase subtilisin/kexin type 9 (PCSK-9) inhibitors can lower Lp(a) levels significantly and should be investigated.

Key Words: lipoprotein(a); cardiac outcomes; cholesterol; coronary artery disease; cardiac risk

\section{Abbreviations}

Apo (a): Apolipoprotein(a)

ApoB100: ApolipoproteinB100

ASCVD: Atherosclerotic Cardiovascular Disease

ATVAB: Arteriosclerosis, Thrombosis, and Vascular Biology

AS: Aortic Valve Stenosis

CAC: Coronary Artery Calcium

CAD: Coronary Artery Disease

CDC: Center for Disease Control

CHOICE: Choices for Healthy Outcomes in Caring for End Stage Renal Disease

CVE: Cardiovascular Event

CVD: Cardiovascular Disease

dL: deciliter

ELISA: Enzyme-linked Immunosorbent Assay
ILSA: Italian Longitudinal Study on Aging

JACC: Journal of the American College of Cardiology

JAHA: Journal of the American Heart Association

JAMA Cardiology: Journal of the American Medical Association Cardiology

L: Liter

Lipids Health Dis.: Lipids in Health and Disease

LMW: Low-molecular weight

Lp (a): Lipoprotein(a)

MACE: Major Adverse Cardiac Event

mg: Milligram

nmol: Nanomole

OPLs: Oxidized Phospholipids

PCSK-9: Proprotein Convertase Subtilisin/Kexin Type 9

SR: Sustained Release

US: United States 


\section{Introduction}

According to the Center for Disease Control (CDC), within the United States (US), 18.2 million adults aged 20 or older have a form of coronary artery disease (CAD), which is a risk factor for other cardiac conditions.[1] Effective treatment can reduce the frequency of major adverse cardiac events (MACEs) in these high-risk individuals if identified early on. [2,3]

Elevated low-density lipoprotein cholesterol (LDL-C) levels, systemic hypertension, smoking, diabetes, and old age are the major, wellestablished risk factors of MACE in general. Nonetheless, a MACE can still occur even if some or all of these factors are controlled. [4] But the effects of lipoprotein (a) [Lp(a)] should not be neglected.

First described in 1963, Lp(a) is an LDL-like particle consisting of an apolipoprotein B100 (apoB100) covalently bonded to an apolipoprotein a [apo(a)] molecule, which exists in multiple "kringles" and contributes to the different $\mathrm{Lp}(\mathrm{a})$ isoforms. [5]

Some studies suggest that lipoprotein(a) [Lp(a)] plasma levels are independently correlated with MACE, which may explain this residual risk. [6] For example, one study found that the risk of acute myocardial infarction (MI) was higher in Chinese patients with normal LDL-C levels, but high Lp(a) levels. [7]

In some cases, $\mathrm{Lp}(\mathrm{a})$ does not appear to increase the risk of certain cardiac conditions but rather aggravate pre-existing conditions. For example, patients with existing aortic valve stenosis (AS) and elevated Lp(a) levels have a higher risk of mortality. [8]

It seems that apo(a) preferentially carries oxidized phospholipids (OPLs), which are highly atherogenic and hasten the disease progression of AS in these individuals. 8 In addition to this, apo(a) appears to have anti-

fibrinolytic and prothrombotic properties. [9]

Notably, serum levels of $\mathrm{Lp}$ (a) are relatively resistant to changes in diet, environment, and lipid-lowering agents. [10,11]

\section{Methodology and Objective}

This review aims to analyze current studies that look at the association between $\mathrm{Lp}$ (a) levels and MACEs independent of the previously mentioned established risk factors. Searches were conducted through the search engines Google, PubMed.gov, and cochrane.org. Websites of various journals, such as the New England Journal of Medicine, Journal of the American Heart Association, Arteriosclerosis, Thrombosis, and Vascular Biology, and Journal of the American College Cardiology, were also pursued.

While many studies have demonstrated a positive correlation between $\mathrm{Lp}$ (a) levels and MACE incidence, there has been controversial data in other studies.

For example, while a study in the Journal of the American College of Cardiology (JACC) found a positive correlation between elevated Lp(a) and MACE for people who already had CAD, the heterogeneity of the studies analyzed did not allow the authors to conclude that $\mathrm{Lp}(\mathrm{a})$ was a useful marker for risk assessment, especially in those with well-controlled LDL-C. [12]

\section{Units of Measurement and Lack of Standardization}

Though measurement of $\mathrm{Lp}$ (a) levels are usually given in $\mathrm{mg} / \mathrm{dL}$, this is not ideal. For example, a study in the Journal of the American Heart Association (JAHA) determined that an Lp(a) level of $\geq 30 \mathrm{mg} / \mathrm{dL}$ was considered "high," while other studies determine an elevated Lp(a) level to be anywhere from $\geq 25 \mathrm{mg} / \mathrm{dL}$ to $\geq 65.2 \mathrm{mg} / \mathrm{dL}$, making recommendations for people with these intermediate $L p(a)$ levels unclear. $[13,14]$ In one systematic review in Lipids in Health and Disease, the authors noted that around half of the secondary prevention studies analyzed treated $\mathrm{Lp}$ (a) levels as categorical variables (such as low, medium, high,) further complicating risk assignment. [13]

\begin{tabular}{|c|c|c|c|c|}
\hline & \multicolumn{4}{|c|}{ Lp(a) Levels } \\
\hline \multirow{5}{*}{$\begin{array}{l}\text { Journal of } \\
\text { Study }\end{array}$} & & Low & Medium & High \\
\hline & JAHA [8] & $\begin{array}{c}<15 \mathrm{mg} / \mathrm{dL} \\
<28.9 \mathrm{nmol} / \mathrm{L}\end{array}$ & $\begin{array}{c}15 \text { to } 30 \mathrm{mg} / \mathrm{dL} \\
28.9 \text { to } 61.6 \mathrm{nmol} / \mathrm{L}\end{array}$ & $\begin{array}{c}>30 \mathrm{mg} / \mathrm{dL} \\
>61.6 \mathrm{nmol} / \mathrm{L}\end{array}$ \\
\hline & $\begin{array}{c}\text { Kidney International } \\
\text { Supplements [9] }\end{array}$ & $\begin{array}{c}<30 \mathrm{mg} / \mathrm{dL} \\
<61.6 \mathrm{nmol} / \mathrm{L}\end{array}$ & & $\begin{array}{c}>30 \mathrm{mg} / \mathrm{dL} \\
>61.6 \mathrm{nmol} / \mathrm{L}\end{array}$ \\
\hline & $\begin{array}{c}\text { Arteriosclerosis, } \\
\text { Thrombosis, and } \\
\text { Vascular Biology [10] }\end{array}$ & - & - & $\begin{array}{c}>73 \mathrm{mg} / \mathrm{dL} \\
>155 \mathrm{nmol} / \mathrm{L}\end{array}$ \\
\hline & $\begin{array}{c}\text { Kidney International } \\
{[11]}\end{array}$ & - & - & $\begin{array}{c}>300 \mathrm{mg} / \mathrm{dL} \\
>650 . \mathrm{nmol} / \mathrm{L}\end{array}$ \\
\hline
\end{tabular}

Table 1: A survey of the various arbitrary categories of $L p(a)$ levels denoted by various studies. Values in red indicate approximate conversions from $\mathrm{mg} / \mathrm{dL}$ to $\mathrm{nmol} / \mathrm{L}$ using the formula in ATVAB.

These types of cutoffs ignore the heterogeneity of apo(a) particles and are a bit arbitrary, as all apo(a) and $\mathrm{Lp}(\mathrm{a})$ particles do not weigh the same. $[13,15]$ There is also no way to accurately convert the units of $\mathrm{mg} / \mathrm{dL}$ into $\mathrm{nmol} / \mathrm{L}$, which measures the number of particles per volume and provides a better representation of $\mathrm{Lp}$ (a) concentration. [16] Unfortunately, some studies have continued to attempt to relate the two measurements, potentially obscuring results. A study in Arteriosclerosis, Thrombosis, and Vascular Biology (ATVAB) used the equation [Lp(a),nmol/L] = 
2.18[Lp(a),mg/dL] - 3.83, where [Lp(a),nmol/L] was the serum $\mathrm{Lp}(\mathrm{a})$ level in units of nmol/L and [Lp(a),mg/L] was the serum $\mathrm{Lp}(\mathrm{a})$ level in units of $\mathrm{mg} / \mathrm{dL}$; such conversions can propagate misleading recommendations. [17] These converted values are included in Table 1 in red.

Studies in the past have been harmed by this lack of standardization. Initial results from a Physician Health Study showed that high levels of $\mathrm{Lp}$ (a) correlated with a higher risk of angina pectoris were later revised. [15] The initial study used enzyme-linked immunosorbent assays (ELISAs), which were sensitive to apo(a) size (i.e. isoform dependent), and the latter used nephelometry. [15] These types of measurements are unfortunately quite common: of the thirty-nine primary prevention studies studied in the systematic review in Lipids in Health and Disease, only twelve studies used isoform independent assays. [13] These assays can also overestimate Lp(a) levels in hypertriglyceridemic individuals. [15]

\section{Other Issues in Handling Samples}

In the systematic review previously mentioned, 34 of the 39 studies didn't use fresh plasma samples when obtaining measurement; however, using frozen plasma is ill-advised for the most accurate measurements. [13] For example, a study in ATVAB found that $\mathrm{Lp}$ (a) plasma levels in samples frozen for between 3 to 28 months were around $4.83 \%$ lower than levels found in fresh samples. [18] This decrease is primarily caused by lowmolecular-weight (LMW) apo(a) isoforms. Since people with atherothrombotic disease more frequently have these LMW apo(a) isoforms, studies using frozen plasma may find an unusually weak correlation between MACEs/ASCVD and Lp(a) levels. [19] This of course complicates the interpretation of studies involving $\mathrm{Lp}(\mathrm{a})$ that utilize frozen plasma.

Even when the proper types of measurements are taken, the prevalence of LMW isoforms may impact studies. The Choices for Healthy Outcomes in Caring for End Stage Renal Disease (CHOICE) study, which used an isoform independent $\mathrm{Lp}$ (a) assay, found that the association between having LMW isoforms and ASCVD was more robust than the association between $\mathrm{Lp}$ (a) levels of $\geq 52.5 \mathrm{nmol} / \mathrm{L}$ and ASCVD in patients on dialysis. $[13,18]$

All else held constant, the specific time of day at which the sample is taken does not seem to affect $\mathrm{Lp}(\mathrm{a})$ measurements significantly. A study in the journal Atherosclerosis found that the median fasting levels of Lp(a) were $17.3 \mathrm{mg} / \mathrm{dL}$, while median levels at 3-4 hours after the last meal were $19.4 \mathrm{mg} / \mathrm{dL}$. [20]

As detailed later, it is prudently advised that further studies be performed following the guidelines provided, as the heterogeneity in the MACE outcomes, populations, and statistical analysis methods means a proper meta-analysis has not been able to be conducted at this point. [13]

\section{Results and Discussion}

\section{Challenges in Lowering Lp(a)}

It is generally agreed that high $\mathrm{Lp}$ (a) levels are correlated with MACEs, though it is unclear whether this is a causal relationship. Some studies contradicted this and determined that Lp(a) had little impact on MACEs. An example of such a study is the Italian Longitudinal Study on Aging (ILSA), which initially found that there was no correlation between high $\mathrm{Lp}(\mathrm{a})$ levels and fatal-nonfatal coronary artery disease (CAD) events. $[13,21]$ However, high $\mathrm{Lp}(\mathrm{a})$ levels were found to be an "independent and significant predictor" after six years in adults between the ages of 65 and 84 years. [13,21]

This increase in risk would not be as problematic if $\mathrm{Lp}(\mathrm{a})$ levels could be consistently lowered with no risk. However, this is not the case.
As stated previously, serum Lp(a) levels and "regular moderate exercise" show no correlation. [10,11] Some studies suggest that people who participate in "intense load-bearing exercise" even have increased Lp(a) levels, though these studies neglected to account for ethnic factors. [11]

Conventional treatments include numerous side effects. Niacin in the amounts needed to treat these dyslipidemia causes "transient, asymptomatic elevations in serum aminotransferase levels" in around $1 / 5$ of people. [22] High doses of sustained-release (SR) niacin tend to cause jaundice and hepatic necrosis, which may be reversible. Some patients may also have underlying liver problems that contraindicate the use of this treatment. [22]

In addition to this, there may be other risks associated with low $\mathrm{Lp}(\mathrm{a})$ levels. A study in the Clinical Chemistry found an inverse relationship between $\mathrm{Lp}$ (a) and type 2 diabetes, independent of other risk factors. [23] It is not conclusively known whether or not this relationship is a causal one. [23]

Other treatments, such as proprotein convertase subtilisin/kexin type 9 (PCSK-9) inhibitors, have shown promise in reducing Lp(a) levels. [24] One such drug, inclisiran, has been especially useful in lowering Lp(a) by $17.2 \%$ from baseline in patients with heterozygous familial hypercholesterolemia who had already been treated with typical statins, according to a study in the New England Journal of Medicine. [25] Small interfering RNA drugs like inclisiran seem roughly as effective as monoclonal antibodies that target PCSK-9; however, inclisiran requires less frequent administrations, increasing the likelihood of patients to adhere to a treatment regimen. [24,25] Since roughly 1 in 250 persons have heterozygous familial hypercholesterolemia, further research into dosing and long-term viability should be considered. [25] This product is still investigational.

\section{The Effect of Lp(a) on Other Cardiac Risk Standards}

Coronary artery calcium (CAC) scores are consistently used to assess CAD risk, especially in asymptomatic individuals.26 A study in the Journal of the American Medical Association Cardiology (JAMA Cardiology) found that adults between the ages of 31 to 46 years who had non-zero calcium scores less than 19 had a 2.6-fold risk of having a MACE in the future than participants who had a score of zero. [27] Another study in the journal Nutrition, Metabolism \& Cardiovascular Diseases found a positive association between Lp(a) levels $>38.64 \mathrm{mg} / \mathrm{dL}$ CAC scores $>0.28$

Whether elevated $\mathrm{Lp}$ (a) contributes to increased risk of CAD independent of elevated CAC score is not decisively known. A study in the Journal of Clinical Lipidology found that for= individuals with a family history of ASCVD, elevated Lp(a) levels (defined as $>50 \mathrm{mg} / \mathrm{dL}$ ) were associated with CAC scores $>100.29$ However, a study in JACC suggested that high $\mathrm{Lp}(\mathrm{a})$ and $\mathrm{CAC}>100$ were independently associated with ASCVD risk.30 While no interaction between these variables was observed in this study, the existence of a joint association between elevated $\mathrm{Lp}(\mathrm{a})$ and CAC score with ASCVD is unclear and requires further research. [30]

\section{Ethnic Factors}

One difference between these studies appears to be the resulting racial distribution from which subjects are chosen, as ethnicity seems to be an influential factor on the cardiac effects of $L p(a)$ in specific individuals. [31] One study in ATVAB noted that an Lp(a) cutoff of $50 \mathrm{mg} / \mathrm{dL}$ might be more appropriate for Caucasians and Hispanics, while a cutoff of $30 \mathrm{mg} / \mathrm{dL}$ is more appropriate for African American individuals in determining cardiac risk. [31]

As discussed before, the units $\mathrm{mg} / \mathrm{dL}$ poorly describe $\mathrm{Lp}$ (a) risk, but is correct in that different cutoffs are needed for different racial groups. different cutoffs are needed for different racial groups. or different racial groups. 


\section{Blacks}

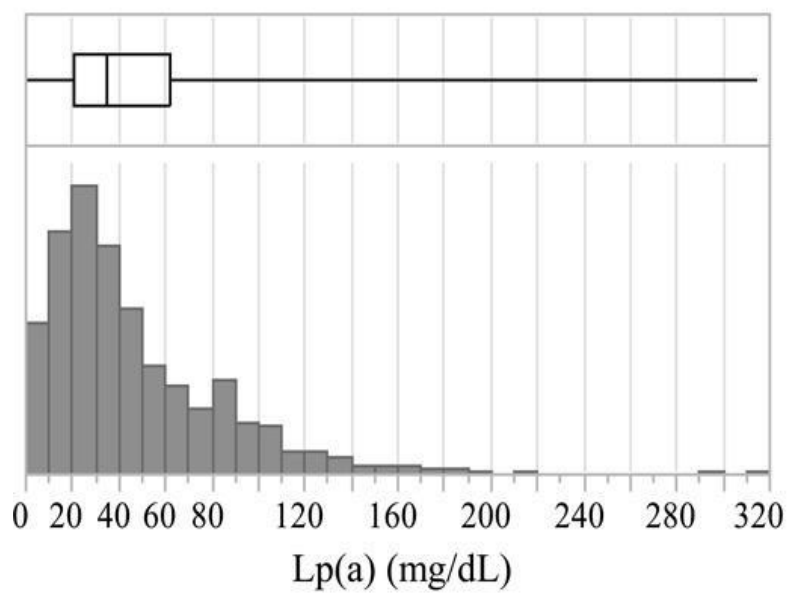

Chinese

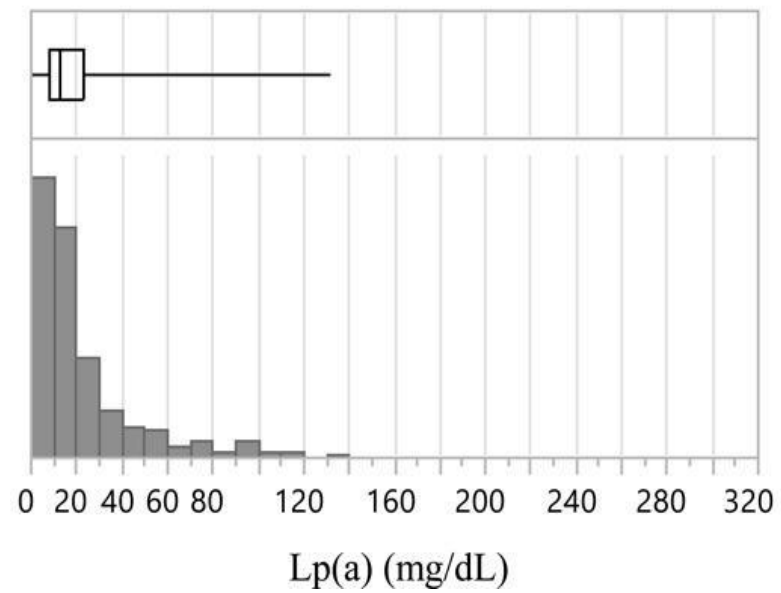

Caucasians

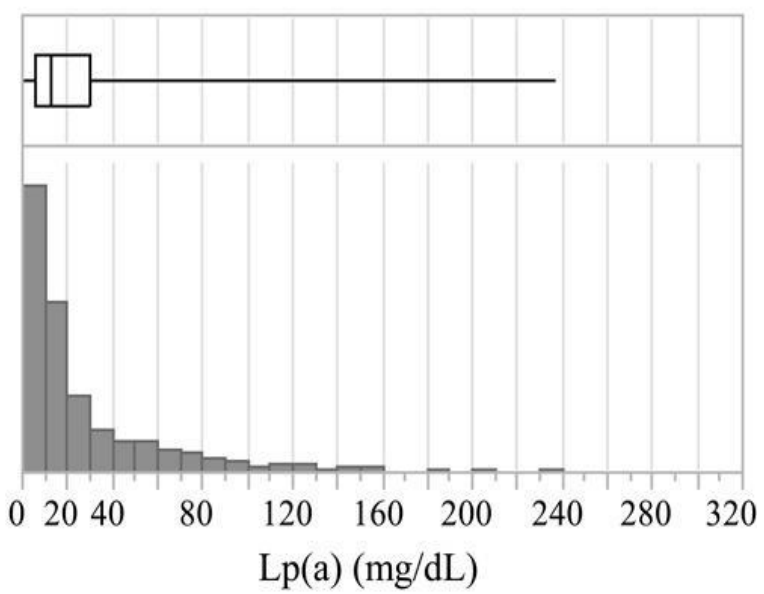

Hispanics

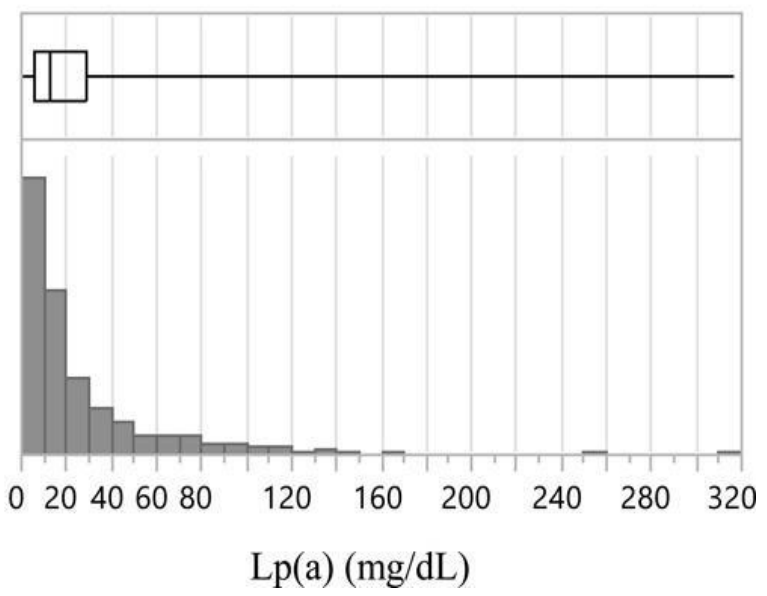

Figure/Table 2: Histogram of $\mathrm{Lp}$ (a) distribution frequency levels by race in the Multi-Ethnic Study of Atherosclerosis; traditional box plot is shown above each histogram denoting first quartile, median, and third quartile. [4]

As seen in Figure 2, different ethnic groups, particularly African Americans, have different distributions of $\mathrm{Lp}(\mathrm{a})$ levels. For example, blacks have a more symmetrical distribution of $\mathrm{Lp}$ (a) levels than Caucasians, Chinese, and Hispanics, implying the need for more flexible cutoffs to determine risk.

High Lp(a) may not be correlated with an increased risk of various cardiac conditions in certain ethnicities. For example, high $\mathrm{Lp}$ (a) levels (in $\mathrm{mg} / \mathrm{dL}$ ) were found to be risk factors for calcific aortic valve disease in white and blacks, but not in Hispanics and Chinese-Americans. [32] High $\mathrm{Lp}$ (a) (in $\mathrm{mg} / \mathrm{dL}$ ) was a risk factor for peripheral artery disease in whites and Hispanics, but not Chinese-Americans or blacks. [33,34] Similarly, a study in ATVAB found that the "Lp(a)-related risk of carotid plaque" was higher in whites than blacks when measured (in $\mathrm{mg} / \mathrm{dL}$ ). [33]

\section{Conclusion}

There is a patent need for a study on $\operatorname{Lp}(\mathrm{a})$ that is isoform independent, accounts of LMW apo(a) isoforms, uses fresh plasma samples, and assigns multiple cutoffs for different ethnic groups. Current studies suffer from one or more of these problems. Lastly, as previously discussed, PCSK-9 inhibitors such as inclisiran show promise and should be further analyzed to identify potential contraindications and long-term effectiveness.

\section{Acknowledgements}

We would like to thank Dr. Sarabjeet Singh, the corresponding author, for his assistance in editing the manuscript. This research did not receive any specific grant from funding agencies in the public, commercial, or notfor-profit sectors. The authors declare no conflict of interest.

\section{References}

1. Heart Disease Facts. Centers for Disease Control and Prevention. https://www.cdc.gov/heartdisease/facts.htm. Published June 22, 2020. Accessed August 10, 2020.

2. Garg S, Serruys PW. Coronary stents: current status. J Am Coll Cardiol. 2010; 56(10 Suppl):S1-S42. doi:10.1016/j.jacc.2010.06.007.

3. Cannon CP, Braunwald E, McCabe $\mathrm{CH}$, et al. Pravastatin or Atorvastatin Evaluation and Infection Therapy-Thrombolysis in Myocardial Infarction 22 Investigators. Intensive versus moderate lipid lowering with statins after acute coronary syndromes. N Engl J Med. 2004; 350:1495-1504. doi:10.1056/NEJMoa040583

4. Kiani F, Hesabi N, Arbabisarjou A. Assessment of Risk Factors in Patients With Myocardial Infarction. Glob J Health Sci. 2015;8(1):255-262. doi:10.5539/gjhs.v8n1p255

5. Siekmeier R, Scharnagl H, Kostner GM, et al. Lipoprotein(a) Structure, Epidemiology, Function and Diagnostics of a 
Cardiovascular Risk Marker. Open Clin Chem J. 2008;1:79-91. doi: 10.2174/1874241600801010079.

6. Nicholls SJ, Tang WH, Scoffone H, et al. Lipoprotein(a) levels and long-term cardiovascular risk in the contemporary era of statin therapy. J Lipid Res. 2010;51(10):3055-61. doi: 10.1194/jlr.M008961.

7. Cai G, Huang Z, Zhang B, Yu L, et al. Elevated lipoprotein (a) levels are associated with the acute myocardial infarction in patients with normal low-density lipoprotein cholesterol levels. Biosci Rep. 2019;39(4)BSR20182096. doi:10.1042/BSR20182096

8. Schnitzler JG, Ali L, Groenen AG, et al. Lipoprotein(a) as Orchestrator of Calcific Aortic Valve Stenosis. Biomolecules. 2019;9(12):760. doi:10.3390/biom9120760

9. Spence JD, Koschinsky M. Mechanisms of lipoprotein(a) pathogenicity: prothrombotic, proatherosclerotic, or both? Arterioscler Thromb Vasc Biol. 2012;32(7):1550-1551. doi: 10.1161/ATVBAHA.112.251306.

10. Siekmeier R, Scharnagl H, Kostner GM, et al. Lipoprotein(a) Structure, Epidemiology, Function and Diagnostics of a Cardiovascular Risk Marker. Open Clin Chem J. 2008;1:79-91. doi: 10.2174/1874241600801010079.

11. Mackinnon LT, Hubinger LM. Effects of exercise on lipoprotein(a). Sports Med. 1999;28(1):11-24. doi:10.2165/00007256-199928010-00002

12. O'Donoghue ML, Morrow DA, Tsimikas S, et al. Lipoprotein(a) for risk assessment in patients with established coronary artery disease. J Am Coll Cardiol. 2014;63(6):520-527. doi:10.1016/j.jacc.2013.09.042

13. Forbes CA, Quek RG, Deshpande S, et al. The relationship between Lp(a) and CVD outcomes: a systematic review. Lipids Health Dis. 2016;15:95. doi:10.1186/s12944-016-0258-8

14. Liu HH, Cao YX, Jin JL, et al. Predicting Cardiovascular Outcomes by Baseline Lipoprotein(a) Concentrations: A Large Cohort and Long-Term Follow-up Study on Real-World Patients Receiving Percutaneous Coronary Intervention. J. Am. Heart Assoc. 2020;9(3). doi:10.1161/JAHA.119.014581

15. Marcovina SM, Albers JJ. Lipoprotein (a) measurements for clinical application. J Lipid Res. 2016;57(4):526-537. doi:10.1194/jlr.R061648

16. Rifai N, Ma J, Sacks FM, et al. Apolipoprotein(a) Size and Lipoprotein(a) Concentration and Future Risk of Angina Pectoris with Evidence of Severe Coronary Atherosclerosis in Men: The Physicians' Health Study. Clinical Chemistry. 2004;50(8):13641371 doi: 10.1373/clinchem.2010.146779

17. Madsen CM, Kamstrup PR, Langsted A, et al. Lipoprotein(a)Lowering by $50 \mathrm{mg} / \mathrm{dL}$ ( $105 \mathrm{nmol} / \mathrm{L})$ May Be Needed to Reduce Cardiovascular Disease $20 \%$ in Secondary Prevention: A Population-Based Study. Arterioscler Thromb Vasc Biol. 3 Oct 2019;40:255-266. doi: 10.1161/ATVBAHA.119.312951

18. Longenecker JC, Klag MJ, Marcovina SM, et al. High lipoprotein(a) levels and small apolipoprotein(a) size prospectively predict cardiovascular events in dialysis patients. $\mathbf{J}$ Am Soc Nephrol. 2005;16(6):1794-1802. doi:10.1681/ASN.2004110922

19. Kronenberg F, Trenkwalder Evi, Dieplinger Hans, et al. Lipoprotein(a) in Stored Plasma Samples and the Ravages of Time: Why Epidemiological Studies Might Fail. Arterioscler Thromb Vasc Biol. 1996;16:1568-1572. doi: 10.1161/01.ATV.16.12.1568

20. Langsted A, Kamstrup PR, Nordestgaard BG. Lipoprotein(a): fasting and nonfasting levels, inflammation, and cardiovascular risk. Atherosclerosis. doi:10.1016/j.atherosclerosis.2014.01.049
21. Solfrizzi V, Colacicco AM, D'Introno A, et al. All-cause mortality and competing risks of fatal and nonfatal vascular events in the Italian longitudinal study on aging: impact of lipoprotein(a). Rejuvenation Res. 2009;12(6):395-402. doi:10.1089/rej.2009.0865

22. LiverTox: Clinical and Research Information on Drug-Induced Liver Injury [database online]. Bethesda (MD): National Institute of Diabetes and Digestive and Kidney Diseases; 2012-. Niacin. [Updated 2014 Feb 2]. Available from: https://www.ncbi.nlm.nih.gov/books/NBK548176/

23. Mora S, Kamstrup PR, Rifai N, et al. Lipoprotein(a) and Risk of Type 2 Diabetes. Clinical Chemistry. 2010;56(8):1252-1260. doi:10.1373/clinchem.2010.146779

24. Ray KK, Wright S, Kallend D, et al. Two Phase 3 Trials of Inclisiran in Patients with Elevated LDL Cholesterol. N Engl J Med. 2020;382:1507-1519. Doi: 10.1056/NEJMoa1912387

25. Raal FJ, Kallend D, Ray KK, et al. Inclisiran for the Treatment of Heterozygous Familial Hypercholesterolemia. N Engl J Med 2020;382:1520-1530. doi: 10.1056/NEJMoa1913805

26. Greenland P, Blaha MJ, Budoff MJ, et al. Coronary Calcium Score and Cardiovascular Risk. J Am Coll Cardiol. 2018;72(4):434-447. doi: 10.1016/j.jacc.2018.05.027

27. Carr JJ, Jacobs DR, Terry JG, et al. Association of Coronary Artery Calcium in Adults Aged 32 to 46 Years With Incident Coronary Heart Disease and Death. JAMA Cardiol. 2017;2(4):391-399. doi:10.1001/jamacardio.2016.5493

28. Sung KC, Wild SH, Byrne CD. Lipoprotein (a), metabolic syndrome and coronary calcium score in a large occupational cohort. Nutr Metab Cardiovasc Dis. 2013;23(12):1239-1246. doi:10.1016/j.numecd.2013.02.009

29. Verweij SL, de Ronde MWJ, Verbeek R, et al. Elevated lipoprotein(a) levels are associated with coronary artery calcium scores in asymptomatic individuals with a family history of premature atherosclerotic cardiovascular disease. J. Clin. Lipidol. 2018;12(3):597-603. doi:10.1016/j.jacl.2018.02.007

30. Nestor Vasquez, Anurag Mehta, Colby Ayers, et al. LIPOPROTEIN(A) AND CORONARY ARTERY CALCIUM SCORE FOR PREDICTING ATHEROSCLEROTIC CARDIOVASCULAR DISEASE RISK. J Am Coll Cardiol. 2020;75(11) 1846. doi: 10.1016/S0735-1097(20)32473-6

31. Guan W, Cao J, Steffen BT, et al. Race is a key variable in assigning lipoprotein(a) cutoff values for coronary heart disease risk assessment: the Multi-Ethnic Study of Atherosclerosis. Arterioscler Thromb Vasc Biol. 2015;35(4):996-1001. doi:10.1161/ATVBAHA.114.304785

32. Cao J, Steffen BT, Budoff M, et al. Lipoprotein(a) levels are associated with subclinical calcific aortic valve disease in white and black individuals: the Multi-Ethnic Study of Atherosclerosis. Arterioscler Thromb Vasc Biol. 2016; 36:1003-1009. doi: 10.1161/ATVBAHA.115.306683

33. Steffen BT, Thanassoulis G, Duprez D, et al. Race-Based Differences in Lipoprotein(a)-Associated Risk of Carotid Atherosclerosis: The Multi-Ethnic Study of Atherosclerosis. Arterioscler Thromb Vasc Biol. 2019;39:523-529. doi: 10.1161/ATVBAHA.118.312267

34. Forbang NI, Criqui MH, Allison MA, et al. Sex and ethnic differences in the associations between lipoprotein(a) and peripheral arterial disease in the Multi-Ethnic Study of Atherosclerosis. J Vasc Surg. 2016; 63:453-458. doi: 10.1016/j.jvs.2015.08.114

35. Koda Y, Nishi S, Suzuki M, et al. Lipoprotein(a) is a predictor for cardiovascular mortality of hemodialysis patients. Kidney Int Suppl. 1999;71:S251-S253. doi:10.1046/j.15231755.1999.07167.x 
36. Nestel PJ, Barnes EH, Tonkin AM, et al. Plasma lipoprotein(a) concentration predicts future coronary and cardiovascular events in patients with stable coronary heart disease. Arterioscler Thromb Vasc Biol. 2013;33(12):2902-2908.
37. Pernod G, Bosson JL, Golshayan D, et al. Phenotypic and genotypic risk factors for cardiovascular events in an incident dialysis cohort. Kidney Int. 2006;69(8):1424-1430. doi:10.1038/sj.ki.5000312
Ready to submit your research? Choose Auctores and benefit from:

* fast, convenient online submission

* rigorous peer review by experienced research in your field

* rapid publication on acceptance

* authors retain copyrights

* unique DOI for all articles

* immediate, unrestricted online access

At Auctores, research is always in progress.

Learn more www.auctoresonline.org/journals/clinical-cardiology-andcardiovascular-interventions 